From: TALE 2014 Conference Secretariat tale-conference@conftool.net

Subject: TALE 2014: New Submission Received. Contribution ID: 53

Date: August 31, 2014 5:58

To: hepidad@gmail.com

Cc:120d9307@st.kumamoto-u.ac.jp, kubota@cs.miyazaki-u.ac.jp, musashi@cc.kumamoto-u.ac.jp, sugitani@cc.kumamoto-u.ac.jp

Dear Mr. Irwan Alnarus Kautsar,

We have received your submission. Thank you.

Submission Details

$======$

Contribution ID: 53

Type : Work-in-Progress

Title : Redefining Data Provider: The REST Approach To Solve

Indonesia Lecturer Administrative Problems.

Author(s) : Kautsar, Irwan Alnarus; Kubota, Shin-Ichiro; Musashi, Yasuo;

Sugitani, Kenichi

Presenting Author: Kautsar, Irwan Alnarus

Presenter's E-mail: hepidad@gmail.com

Uploaded Files

$=============$

1st file : TALE2014-Irwan.docx

Last Upload: 31st Aug 2014, 10:58:26am NZST

With best regards,

Your TALE 2014 organizers.

IEEE International Conference on Teaching, Assessment and Learning for Engineering 2014

https://www.conftool.net/tale-conference/ 
From: TALE 2014 Conference Secretariat tale-conference@conftool.net

Subject: TALE 2014 - Notification of Acceptance

Date: October 22, 2014 16:27

To: hepidad@gmail.com

Cc: 120d9307@st.kumamoto-u.ac.jp, hepidad@gmail.com, kubota@cs.miyazaki-u.ac.jp, musashi@cc.kumamoto-u.ac.jp, sugitani@cc.kumamoto-u.ac.jp

Dear Irwan Alnarus Kautsar,

Thank you very much once again for submitting a paper to the 2014 IEEE International Conference on Teaching, Assessment and Learning for Engineering (TALE). On behalf of the TALE 2014 Program Committee, we are pleased to inform you that your submission has been accepted for presentation at the conference, subject to the reviewers' feedback being satisfactorily addressed. The review results are appended at the end of this email.

Please begin making revisions to your paper in light of the reviewers' feedback. The final version of your paper must be uploaded to the conftool system (https://www. conftool.net/tale-conference/) no later than October 31, 23:59 NZST (UTC+12, displayed here:

https://www.conftool.net/tale-conference/). At least one author must also register for the conference on or before this date in order for the paper to be included in the conference program and published in the conference proceedings and in IEEE Xplore.

When preparing your final paper, it is imperative that you consult the Style Guide on the conference website (http://tale-conference.org/tale2014/papers.php). Of particular importance is that you pay attention to the following; failure to do so may result in your paper being excluded from the proceedings and from IEEE Xplore:

1. You MUST prepare your final paper using the MS-Word paper template provided. Use of any other IEEE templates (including IEEE's LaTeX template) is not acceptable as there are subtle differences between those templates and the conference template that will affect the consistency in appearance of papers published in the proceedings.

2. The page limits must be strictly adhered to (Regular Papers should be between 4 and 6 pages in length).

3. The abstract must be no longer than 100 words.

4. Page headers and footers must not include any information whatsoever (no page numbers, etc). They must be completely EMPTY.

5. Page margins must be set to the following dimensions: Top $=1.9 \mathrm{~cm}$, Bottom:

$4.29 \mathrm{~cm}$, Left: $1.29 \mathrm{~cm}$, Right: $1.29 \mathrm{~cm}$.

6. Paper size must be A4, not Letter or anything else

7. You are required to upload both MS-Word and PDF versions of your final paper to the conftool system. To reiterate, the Word template available on the conference website must be used; the PDF version of your paper should be generated from the Word version. "Reverse engineering" of the Word version from the PDF version is not acceptable.

8. When submitting the final paper, your must ensure you complete the electronic copyright form. This will be part of the process you complete on the conference website when you submit the paper.

Finally, please note that we take the integrity of papers very seriously. All final papers will be subjected to automated checking using the CrossCheck tool, and any cases of suspected plagiarism (including self-plagiarism) will be reported to IEEE. Authors whose papers are found to have been plagiarised will have their papers removed from the conference program and proceedings. By submitting your final paper via conftool you warrant that it is original and that it is your own work, and that it has not been published nor is it under consideration for publication elsewhere, whether in part or in whole.

Congratulations on the acceptance of your paper! Should you have any additional questions, please feel free to contact us. We look forward to seeing you in New Zealand in December.

Yours sincerely,

Henry Chan

Ford Lumban Gaol

TALE 2014 Technical Program Co-Chairs

Dale Carnegie

TALE 2014 General Chair

Craia Watterson 
Institutional Sign In

BROWSE

\begin{tabular}{l||l} 
MY SETTINGS & GET HELP
\end{tabular}

WHAT CAN I ACCESS?

SUBSCRIBE

Browse Conferences > Teaching, Assessment and Lear...

<Previous | Back to Results | Next >

\title{
Redefining Data Provider: The REST approach To solve Indonesia Lecturer administrative problems
}

$$
\begin{array}{lll}
\text { Sign In or Purchase } & \mathbf{1} & \mathbf{2 9} \\
\text { to View Full Text } & \text { Paper } & \text { Full } \\
& \text { Citation } & \text { Text Views }
\end{array}
$$

\section{Related Articles}

The ABELS brokering system

Reconfiguration of resources in middleware

Distributed object-oriented real-time simulation of the multicast protocol RFRM

\begin{tabular}{|c|c|c|c|c|c|c|c|}
\hline $\begin{array}{c}4 \\
\text { Author(s) }\end{array}$ & Irwan Alnarus Kautsar ; & Shin-Ichiro Kubota ; Y & Musashi ; & chi Sugitani & & & View All Authors \\
\hline Abstract & Authors & References & Citations & Keywords & Metrics & Media & \\
\hline
\end{tabular}

View All

\begin{abstract}
:
Directorate General Higher Education Institution of Indonesia (DGHEI), request lecturers to provide data or report their academic activities as evidence of them. Lecturers needs to make a portfolio or other document specified by DGHEI. From now on we will call this administrative issues. These issues are becoming a problem when the DGHEI requests these reports from the Lecturers to be updated in the DGHEI Systems in a specific time frame. The present paper discusses the problems that appear in the current system. Some of the problems that Lecturers face are: DGHEI Information Systems service unavailability. As a result of this analysis, a new methodology is proposed in order to solve these issues and others. The new approach, using REST (Representational Sate Transfer) to provide the lecturer data in a distributed manner, allowing sharing capabilities to the current system.
\end{abstract}

Published in: Teaching, Assessment and Learning (TALE), 2014 International Conference on

Date of Conference: 8-10 Dec. 2014

INSPEC Accession Number: 14999514

Date Added to IEEE Xplore: 19 March 2015

DOI: 10.1109/TALE.2014.7062614

Electronic ISBN: 978-1-4799-7672-0

Publisher: IEEE

Conference Location: Wellington, New Zealand

\begin{tabular}{l} 
Download PDF \\
Download Citations \\
\hline View References \\
\hline Email \\
\hline Print \\
\hline
\end{tabular}

Request Permissions

\section{Read the full document}

\section{Keywords}

\section{IEEE Keywords}

Information systems, Education, Protocols, Web servers, Portfolios

\section{INSPEC: Controlled Indexing}

information systems, educational administrative data processing, educational institutions, further education

\section{INSPEC: Non-Controlled Indexing}

representational state transfer, data provider, Indonesia lecturer administrative problems,

Directorate General Higher Education Institution of Indonesia, academic activities, lecturer portfolio,
Abstract

Authors

Figures

References

Citations

Keywords

Back to Top 


\section{TALE2014 Committees}

\section{Honorary Advisors}

- Manuel Castro, President, IEEE Education Society

- Russ Meier, IEEE Education Society

\section{Organizing Committee}

\section{General Chair}

- Dale Carnegie, Victoria University of Wellington, New Zealand

\section{General Co-Chair}

- Craig Watterson, Victoria University of Wellington, New Zealand

\section{Steering Committee Chair}

- Russ Meier, IEEE Education Society

\section{Technical Program Co-Chairs}

- Henry C. B. Chan, The Hong Kong Polytechnic University, Hong Kong SAR

- Ford Lumban Gaol, BINUS University, Indonesia

\section{Publication Co-Chairs}

- Michael E. Auer, CTI, Austria

- Sebastian Schreiter, IAOE, France

\section{Publicity Chairs}

- Hai-Ning Liang, Xi'an Jiaotong-Liverpool University, China

\section{Secretariat and Registration Co-Chairs}

- Sue Hall, Victoria University of Wellington, New Zealand

- Craig Watterson, Victoria University of Wellington, New Zealand

Treasury Chair

- Sue Hall, Victoria University of Wellington, New Zealand

\section{Local Arrangement Chairs}

- Craig Watterson, Victoria University of Wellington, New Zealand

- Sue Hall, Victoria University of Wellington, New Zealand 


\section{TALE2014 Reviewers}

- Jagadeesh Chandra A. P., India

- Chekry Abderrahman, Morocco

- Norliza Abdul Rahman, Malaysia

- Aminat Abdul-Salaam, Nigeria

- Mounia Abik, Morocco

- Joerg Abke, Germany

- Shatha Abu Shanab, Palestinian Territories

- Greg Adamson, Australia

- Adrian A. Adascalitei, Romania

- Abdelkader Adla, Algeria

- Oleagordia Aguirre, Spain

- Muhammad Ovais Ahmad, Finland

- Noor Azlan Ahmad Zanzali, Malaysia

- Mohammed Ali Akour, Oman

- Hend Al-Khalifa, Saudi Arabia

- Salvador Alcaraz, Spain

- Daniyal Mohammed Alghazzawi, Saudi Arabia

- Saleh M. Alhazbi, Qatar

- Teresa Alvarez, Spain

- Latha Anantharaman, India

- Gerardo Aranguren, Spain

- Francisco J. Arcega, Spain

- Ana Arruarte, Spain

- Galina Artyushina, Russia

- Isabel Azevedo, Portugal

- Balamuralithara Balakrishnan, Malaysia

- Monica Banzato, Italy

- Ana M. Barbancho, Spain

- Fernando Maciel Barbosa, Portugal

- Ricardo Barcelos, Brazil

- Nigan Bayazit, Turkey

- Chellali Benachaiba, Algeria

- Abdelhalim Benachenhou, Algeria

- Endika Bengoetxea, Spain

- Hana Bensalem, Algeria

- Sharbani Bhattacharya, India

- Badre Bossoufi, Belgium

- Axel C.H. Böttcher, Germany

- Ahmed Boubakeur, Algeria

- Christos Bouras, Greece

- Agustin C. Caminero, Spain

- Edgar Manuel Cano Cruz, Mexico

- Paulo Cardoso, Portugal

- Dale Anthony Carnegie, New Zealand

- German Carro Fernandez, Spain

- Jovani Castelan, Brazil

- Manuel Castro, Spain

- Aydin Cetin, Turkey

- Laila Cheikhi, Morocco

- Dyi-Cheng Chen, Taiwan, R.O.C. 


\section{Programme}

Sunday 7 December 2014

\begin{tabular}{|l|c|}
\hline $\begin{array}{l}\text { 9:30- } \\
\text { 3:00 }\end{array}$ & Full day Workshop on PSoC (Cypress University Alliance) \\
\hline $9: 00-$ & Rangimarie 2, Level 3, Te Papa \\
4:30 & AAEE Executive Committee Meeting \\
\hline 6:30 - & Rangimarie 3, Level 3, Te Papa \\
7:30 & Welcome Reception \\
& Signs of a Nation, Level 4, Te Papa, 6.30PM-7.30PM \\
\hline
\end{tabular}

Monday 8 December 2014

\begin{tabular}{|c|c|c|c|c|c|c|c|}
\hline & \multicolumn{7}{|c|}{$\begin{array}{c}\text { Maori Welcome: 8:30AM } \\
\text { Sounding Theatre, Level 2, Te Papa Tongarewa National Museum of New Zealand } \\
\text { Registration and Exhibition space: 8:00AM - 5:00PM Oceania, Level 3, Te Papa }\end{array}$} \\
\hline $\begin{array}{l}9: 00- \\
10: 00\end{array}$ & \multicolumn{7}{|c|}{$\begin{array}{c}\text { Steve Maharey - Vice-Chancellor, Massey University: Official Opening } \\
\text { Sounding Theatre, Level } 2 \\
\text { Keynote Speaker Professor Alison Halstead - Sponsored by AKO Aotearoa } \\
\text { Pathways: How do we ensure that all learners are enabled to make connections across areas } \\
\text { of learning that support an education in engineering? }\end{array}$} \\
\hline $\begin{array}{l}10: 00- \\
10: 30\end{array}$ & \multicolumn{7}{|c|}{ Morning Tea - Oceania, Level 3, Te Papa } \\
\hline & $\begin{array}{l}\text { Sounding } \\
\text { Theatre }\end{array}$ & Icon & $\begin{array}{l}\text { Oceania } \\
\text { North }\end{array}$ & $\begin{array}{l}\text { Oceania } \\
\text { South }\end{array}$ & $\begin{array}{l}\text { Angus } \\
\text { Room }\end{array}$ & $\underset{1}{\text { Rangimarie }}$ & $\underset{2}{\text { Rangimarie }}$ \\
\hline $\begin{array}{l}10: 30- \\
12: 00\end{array}$ & $\begin{array}{l}\text { Session 1A } \\
\text { Collaborative } \\
\text { Pathways }\end{array}$ & $\begin{array}{l}\text { Session 1B } \\
\text { Electrical } \\
\text { Engineering }\end{array}$ & $\begin{array}{l}\text { Session 1C } \\
\text { Global } \\
\text { Competitive } \\
\text { Supply of } \\
\text { Engineers }\end{array}$ & $\begin{array}{l}\text { Session 1D } \\
\text { Student } \\
\text { Engagement } \\
\text { \& Retention }\end{array}$ & $\begin{array}{l}\text { Session 1E } \\
\text { Introductory } \\
\text { Engineering \& } \\
\text { Computing } \\
\text { Courses \& } \\
\text { Learning } \\
\text { Management } \\
\text { Systems } \\
\text { TALE } \\
\text { Chair: } \\
\text { Prof Dale } \\
\text { Carnegie }\end{array}$ & $\begin{array}{l}\text { Session 1F } \\
\text { Assessment } \\
\text { and } \\
\text { Evaluation-1 } \\
\text { TALE }\end{array}$ & $\begin{array}{l}\text { Session 1G } \\
\text { Teaching } \\
\text { Approaches-1 } \\
\text { TALE }\end{array}$ \\
\hline $\begin{array}{l}12: 00- \\
1: 30\end{array}$ & \multicolumn{7}{|c|}{ Lunch - Oceania, Level 3, Te Papa } \\
\hline $\begin{array}{l}1: 30- \\
3: 00\end{array}$ & $\begin{array}{l}\text { Workshop } \\
\text { 1A } \\
\text { Solving } \\
\text { wicked } \\
\text { sustainability } \\
\text { problems: } \\
\text { What specific } \\
\text { knowledge } \\
\text { and skills do } \\
\text { students need } \\
\text { to have to } \\
\text { solve modern } \\
\text { sustainability } \\
\text { issues and } \\
\text { those of the } \\
\text { future? }\end{array}$ & $\begin{array}{l}\text { Workshop } \\
\text { 1B } \\
\text { Addressing the } \\
\text { Publication } \\
\text { Review } \\
\text { Criteria for the } \\
\text { IEEE } \\
\text { Transactions } \\
\text { on Education } \\
\text { TALE }\end{array}$ & $\begin{array}{l}\text { Workshop } \\
\text { 1C } \\
\text { Preparing } \\
\text { Students for } \\
\text { Gendered } \\
\text { Workplaces }\end{array}$ & $\begin{array}{l}\text { Workshop } \\
\text { 1D } \\
\text { Supporting } \\
\text { diverse student } \\
\text { cohorts } \\
\text { through their } \\
\text { engineering } \\
\text { studies }\end{array}$ & $\begin{array}{l}\text { Session 2E } \\
\text { Work in } \\
\text { Progress }\end{array}$ & $\begin{array}{l}\text { Session 2F } \\
\text { Curriculum } \\
\text { Design and } \\
\text { Pedagogy-2 } \\
\text { TALE }\end{array}$ & $\begin{array}{l}\text { Session 2G } \\
\text { Educational } \\
\text { Resources, } \\
\text { Distance, } \\
\text { Open and } \\
\text { Flexible } \\
\text { Education } \\
\text { TALE } \\
\\
\text { Chair: } \\
\text { Dr Bryan Ng }\end{array}$ \\
\hline $3-3: 30$ & \multicolumn{7}{|c|}{ Afternoon Tea - Oceania, Level 3, Te Papa } \\
\hline $\begin{array}{l}3: 30- \\
5: 00\end{array}$ & $\begin{array}{l}\text { Workshop } \\
\text { 1A } \\
\text { (continue) } \\
\text { Solving } \\
\text { wicked } \\
\text { sustainability } \\
\text { problems. }\end{array}$ & $\begin{array}{l}\text { Workshop } \\
\text { 1B } \\
\text { (continue) } \\
\text { Addressing the } \\
\text { Publication } \\
\text { Review } \\
\text { Criteria for the } \\
\text { IEEE } \\
\text { Transactions } \\
\text { on Education } \\
\text { TALE }\end{array}$ & $\begin{array}{l}\text { Workshop } \\
\text { 2C } \\
\text { What goes on, } \\
\text { comes around: } \\
\text { Exploring the } \\
\text { affordances of } \\
\text { engineering } \\
\text { laboratory } \\
\text { venues and } \\
\text { how to interpret } \\
\text { these for } \\
\text { proposed face- } \\
\text { to-face and } \\
\text { online venues. }\end{array}$ & $\begin{array}{l}\text { Workshop } \\
\text { 2D } \\
\text { Cultivating } \\
\text { Curiosity: } \\
\text { Improving } \\
\text { Metacognition } \\
\text { and Motivation } \\
\text { and Revealing } \\
\text { Misconception } \\
\text { s in } \\
\text { Engineering } \\
\text { Students }\end{array}$ & $\begin{array}{l}\text { Session 3E } \\
\text { Work in } \\
\text { Progress on } \\
\text { Student } \\
\text { Engagement \& } \\
\text { Retention }\end{array}$ & $\begin{array}{l}\text { Session 3F } \\
\text { Collaborative } \\
\text { Pathways }\end{array}$ & $\begin{array}{l}\text { Session } 3 \mathbf{G} \\
\text { Learning and } \\
\text { Teaching } \\
\text { Approaches } \\
\text { TALE }\end{array}$ \\
\hline
\end{tabular}


Monday 8 December 2014

\section{Session 2F - Curriculum Design and Pedagogy - 2 (TALE) Rangimarie 1 \\ Chair: Dr Phillip Allen}

1. Investigation-in-progress on how to effectively use tablet terminals in science experiment classes performed by a student project team Hasegawa, M., Teshima, S.

2. Integrating Computer Security into the Undergraduate Software Engineering Classes: Lessons Learned Pancho-Festin, S., Mendoza, M.J.

3. A Design Project Based Approach to Teaching Undergraduate Instrumentation Long, D.S., McKay, T.G.

4. Understanding career aspirations of Information Technology students at Deakin University

McKenzie, S.C., Palmer, S., Coldwell-Neilson, J., Coleman, K.

5. Feasibility study on evaluation of audience's concentration in the classroom with deep convolutional neural networks Yoshihashi, R., Shimada, D., lyatomi, $H$.

\section{Session 2G - Educational Resources, Distance, Open and Flexible Education (TALE) \\ Rangimarie 2 \\ Chair: Dr Bryan Ng}

1. Training Laboratory: Using online resources to enhance the laboratory learning experience

Nikolic, S.

2. Facilitating Access to Course Contents During War Situation with MLearning and Cloud Computing Technologies Wannous, M., Nakano, H., Mahfuri, M., Nagai, T.

3. Work in Progress: Simple software solution for accessing remote lab on mobile devices Samuelsen, D.A.H., Bjørk, J., Graven, O.H.

4. Redefining Data Provider: The REST Approach To Solve Indonesia Lecturer Administrative Problems. Kautsar, I.A., Kubota, S.-I. Musashi, Y., Sugitani, K.

5. Familiarity breeds understanding: Recommending explanatory analogies to learners

Kumar, V., Bhat, S.S., Pedanekar, N.

Workshop 1B (cont'd)

ICON

Addressing the Publication Review Criteria for the IEEE Transactions on Education

Froyd, J.E. 


\title{
Redefining Data Provider: The REST Approach To Solve Indonesia Lecturer Administrative Problems.
}

\author{
Irwan Alnarus Kautsar ${ }^{1}$, Shin-Ichiro Kubota ${ }^{2}$, Yasuo Musashi ${ }^{1}$, Kenichi Sugitani ${ }^{1}$ \\ ${ }^{1}$ Department of Computer Science and Electrical Engineering, \\ ${ }^{1}$ Kumamoto University, Kumamoto, Japan. \\ ${ }^{2}$ Department of Computer Science and Systems Engineering, \\ ${ }^{2}$ University of Miyazaki, Miyazaki, Japan. \\ 120D9307@st.kumamoto-u.ac.jp, kubota@cs.miyazaki-u.ac.jp, \{musashi, sugitani\}@cc.kumamoto-u.ac.jp
}

\begin{abstract}
Directorate General Higher Education Institution of Indonesia (DGHEI), request lecturers to provide data or report their academic activities as evidence of them. Lecturers needs to make a portfolio or other document specified by DGHEI. From now on we will call this administrative issues. These issues are becoming a problem when the DGHEI requests these reports from the Lecturers to be updated in the DGHEI Systems in a specific time frame. The present paper discusses the problems that appear in the current system. Some of the problems that Lecturers face are: DGHEI Information Systems service unavailability. As a result of this analysis, a new methodology is proposed in order to solve these issues and others. The new approach, using REST (Representational Sate Transfer) to provide the lecturer data in a distributed manner, allowing sharing capabilities to the current system.
\end{abstract}

Keywords-REST Protocol; Distributed Systems; Authoring Tools; DGHEI

\section{INTRODUCTION}

The Directorate General Higher Education Institution of Indonesia (DGHEI) has been using Web as a public service for more than a decade ago. The main role of DGHEI is to manage the Education systems at the higher education level. The main function of the DGHEI is to manage Higher Education Institution's information as well as students and lecturers information from public and private universities.

For lecturers, their duty is not only to provide education related activities, but also administrative services. One of the duties is to write a report about the academic activities done in one semester. The DGHEI provides an online platform to the lecturers in order to upload their reports.

Based on the DGHEI regulations, lecturers are requested to upload data through several DGHEI websites. Which are Sertifikasi Dosen/Lecturer Certification System (SERDOS) and Sistem Informasi Pengembangan Karir Dosen/Lecturer Career Development Information System (SIPKD). Also, there was another website called FORLAP, used by academic staff to report recent or update data about detailed University's condition. Such as, the number of newcomers, a number of lecturers engaged in active teaching.

The reasons why DGHEI was the pioneer institution to use the web as a public service, was to reduce the information sharing time and to improve the accessibility to lecturer data.

However, the use of these services create other problems. Which is, in fact, repetitive activities by the user (lecturer and academic staff) when uploading data. For example, as a regulation, the lecturer should upload data on two DGHEI websites, and academic staff should upload only on FORLAP. The uploaded data is almost similar entity data. Such as Curriculum Vitae, Academic activity.

Another web application that is maintained by DGHEI is STUDI DIKTI, an Information System (IS) for lecturers that received the DGHEI scholarships. The awardees should report their academic/study activity to this IS. Once again, these reports contain similar data entity. This reporting/uploading activity could cause several issues, such as: data redundancy, load balancing problems (considering potential user accessing the systems), and user time consuming (for repetitive activities).

This paper presented a Representational State Transfer (REST), a software architecture style that could be used as an approach to solve those problems. With the REST approach, the use of the web as a distributed system is enabled. Our proposed approach, implemented with REST is to develop an application as a supportive tool for lecturers, which can support lecturers to collect and record their academic activities. Afterward, with REST web service, we proposed a novel approach to enable the Institution (the lecturer Homebase) to become Data Provider.

This paper is presented as follows, Section II, Problem Analysis; Section III discusses about REST Approach and Proposed Method; Section IV shows our implementation and Experiment Results; Section V presents our Conclusions and Future Work. 


\section{PROBLEM ANALYSIS}

\section{A. The Current DGHEI Information System}

The main functions of the Information System (IS), is to provide updated data and real time access. The use of web technology as an information system, can wider accessibility and ease of installations compare with Desktop app based Information Systems. The challenge of developing a web based information system is how to develop reliable, high concurrency systems [1]

The information systems, that maintained by DGHEI could be considered as high concurrency system. Because, it can be accessed by more than 10000 potential users, as total lectures from all universities in Indonesia. The DGHEI request lecturers to uploading necessary document on SERDOS and SIPKD. For the Lecturer Institution Administrative staff is required to upload data on FORLAP. Detail IS provided by DGHEI are shown in Table 1.

TABLE I. INFORMATION SYSTEM PROVIDED BY DGHEI.

\begin{tabular}{|l|l|l|}
\hline \multicolumn{1}{|c|}{ Name } & \multicolumn{1}{c|}{ URL } & \multicolumn{1}{c|}{ User } \\
\hline SERDOS & https://serdos.dikti.go.id/ & Lecturer \\
\hline SIPKD & https://sipkd.dikti.go.id/ & Lecturer \\
\hline FORLAP & https://forlap.dikti.go.id/ & $\begin{array}{l}\text { Lecturer, } \\
\text { Academic } \\
\end{array}$ \\
& & Staff, Public \\
\hline
\end{tabular}

\section{1) The FORLAP}

This information system, open to public since July 15, 2013, based on DGHEI letter (No. 1097 /E4.1/ 2013), that replaces the old information system called Evaluasi DIKTI. The main function of the old and new IS is quite similar. Which is to manage data of all elements of some private/public Higher Education Institutions (HEI), active students and lecturers. The advantages of FORLAP are that it has a small probability to have peak season/peak time and concurrent user relatively small. Because the user that is authorized to upload data is just administrative staff. Each one public/private HEI has one user account. But, this service model, have other disadvantages, for example, if there is mistaken data, or data update, the lecturer cannot change directly and quickly. At first, is needed to inform the administrative staff. The other crucial thing is, DGHEI uses data from FORLAP to make decisions or assessments.

\section{2) The SERDOS}

The use of this information system is to evaluate lecture performance. For the need of this evaluation, lecturers are requested to upload data. Not all lecturers can access and upload data to the SERDOS, only selected lecturers by DGHEI. DGHEI uses SERDOS Data to select the lecturer. Again, selected lecturer base on data from the FORLAP. Base on new regulation by DGHEI (No. 3603/E4.3/2012), The data need to be uploaded are: a Curriculum Vitae (CV), Deskripsi Diri (Self Description Document) and another lecturer portfolio. The result of this evaluation is for the lecturer to achieve professional certificate and professional allowances. Same conditions with the FORLAP systems, these have a small chance to have peak time. Because not all lecturers could access the systems. But, data redundancy occurs in these systems, because the lecturer uploading similar document such as curriculum vitae and portfolio in this IS.

\section{3) The SIPKD}

Sistem Informasi Pengembangan Karir Dosen/Lecturer Career Development Information System (SIPKD), used to track what the lecturer has done in one semester. Because of no selective user and DGHEI obligate all lecturers to upload their documents in this IS, the SIPKD server has strong possibility to face a peak time. And as a consequence the server is down. The SIPKD just went down in the first month after been released. To solve this matter, DGHEI made regulation as written in official letter no: 652/E4.1/2014, which regulate a schedule of when SIPKD websites should be accessible. The scheduled access is based on academic rank. Shown in Table 2.

TABLE II. The ACCESSIBILITY DAY BASED ON ACADEMIC RANK

\begin{tabular}{|l|l|l|}
\hline No & \multicolumn{1}{|c|}{$\begin{array}{c}\text { Academic Rank in } \\
\text { Indonesia }\end{array}$} & \multicolumn{1}{|c|}{ Accessibility Day } \\
\hline 1 & $\begin{array}{l}\text { Guru Besar (Professor) } \\
\text { and Lektor Kepala }\end{array}$ & Monday and Tuesday \\
\hline 2 & Lektor & Wednesday a Thursday \\
\hline 3 & Asisten Ahli & $\begin{array}{l}\text { Friday, Saturday and } \\
\text { Sunday }\end{array}$ \\
\hline
\end{tabular}




\section{B. The Entity Data and Problem Issues}

From our perspective, this regulation/solution has several issues such as:

- The use of the web should not have boundaries with time regulations. This rule could not match the lecturer schedule.

- The difference of the amount of lecturers among professors, and lowest level academic degrees, possibly could create peaks on their specific access dates.

- Difference location/demographics of each area in Indonesia, has a different ease of Internet access.

As result of problem analysis, the issues that needed to be addressed are: 1). Lecturer uploads same document: such as CV and portfolio. This cause repetition and redundancy data. How to provide single valid data?. 2). Solve high concurrency DGHEI web application, and need an approach for reliability server when meets peak time.

\section{REST APPROACH AND PROPOSED METHOD}

Representational State Transfer (REST), is bubbling protocol to serve an information with lightweight bandwidth consumption and rock solid protocol to support the use of web as distributed systems [2,3]. The importance of REST paradigm, made REST the best approach for distributed systems. The paradigm are, REST focused on how it could represent resources. With or without REST, the resource can be represented in any format. For example, XML or plain text, shown in Fig. 1.

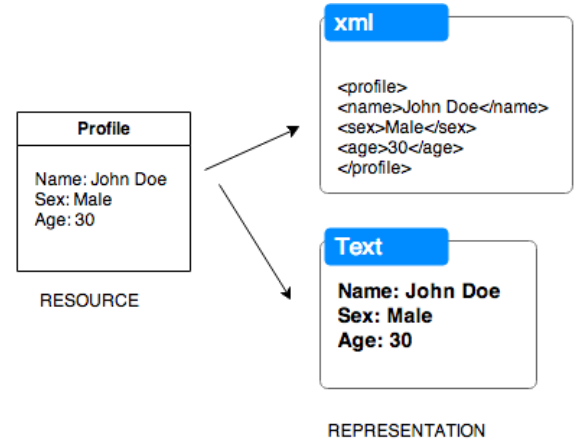

Fig. 1. Resources Representation of Data.

If access the web server where REST is ready, the client will receive the following response: (Fig. 2).

\{

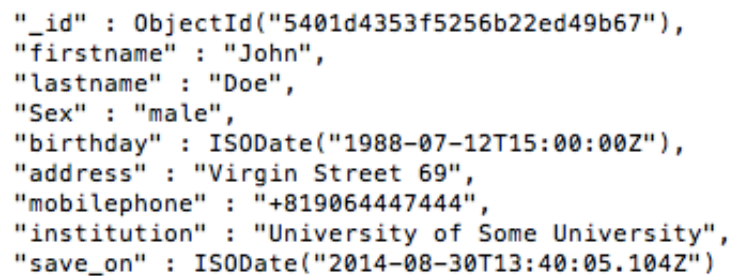

Fig. 2. Response from Web Server that REST ready.

When using the REST approach, the uploaded document by the lecturer is the resource. For this matter, our proposed approach, is answering the research question, how to deliver the resource that can solve the problem mentioned in Section II B, such as peak problems in accessing DGHEI Information Systems.

Technically, to solve the peak problem, the developer implements load balancing agent system $[4,5]$. Instead of developing load balancer, in this paper, we proposed a distributed data collection. Data grabbed/collected institutionally with REST approach. So, the DGHEI IS is not the main target. The traffic is distributed to each lecturer institution. REST protocol runs over HTTP only. Also, through HTTP, the web application is RESTful already, could perform operations like: Create, Read, Update and Delete (CRUD). This makes easy to integrate existing DGHEI Information System with the proposed approach.

We deliver the proposed method by re-defining who is the data provider. To control and avoid redundancy, lecturer data are centralized at their Homebase university. So, lecturers do not need to upload all the data directly to the DGHEI / SIPKD server, but uploading the instrument that is requested to their Institution. Then, the DGHEI/SIPKD server, grabs the lecturer data from the lecturer institutions. 
For our research purposes, we define the following terminology: PDP = Pivot Data Provider. In this case, the lecturer is the PDP. IDP = Institutional Data Provider, the lecturer home base university. IDC = Institutional Data Customer. For the IDC, not only the DGHEI server, but also other institutions like: private companies that are willing to scout information, in order to help the selection process to grant research funds for some public/private higher education institutions. The flow of data between lecturer, IDP and DGHEI is illustrated in Fig. 3.

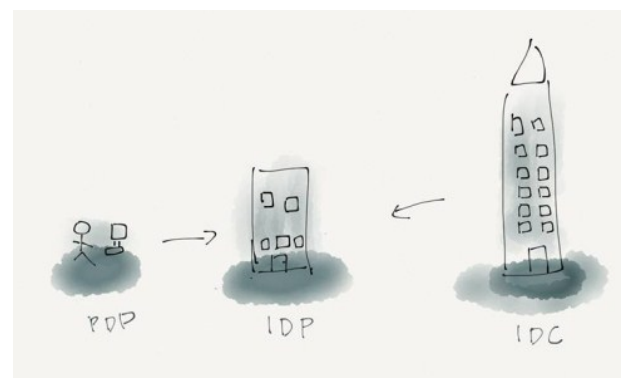

Fig. 3. The Data Flow between PDP, IDP and IDC.

In this research, we simulate data that will be reported by lecturers to DGHEI, using simply lecturer profiles. Such as: Name, Sex, Date of Birth, Address, Moblie Phone, and Institution name. The detail scenario to simulate the data flow activity is shown in Fig. 4.

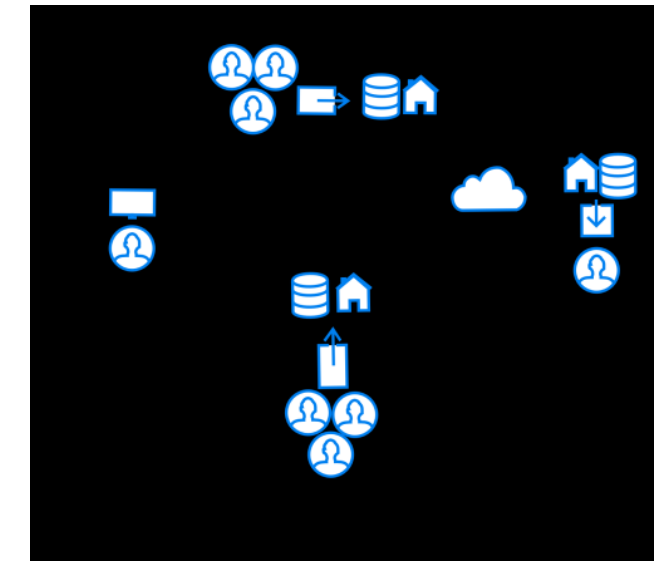

Fig. 4. The Simulation Scenario for REST Approach.

The data flow scenario's activity from the above picture is:

\section{A. Creation.}

Lecturer create/update his public profile that will use on DGHEI as recent Curriculum Vitae. The public profile authoring could be done in a local machine (offline) or web application provided by their campus (online). In this research, we prefer to simulate this proposed method with authoring offline conditions, because this fits more with the real conditions in Indonesia where there are bandwidth gap problems.

\section{B. Uploading.}

After authoring the public profile, we proposed lecturers to upload their profile to their IDP servers. This uploading activity should be done using Local Area Network or Internet as long as IDP has a public IP Address an automatically. For example, when the Lecturer laptop is connected to the server machine, the application that acts as PDP upload automatically the updated data to IDP.

\section{Grabbing.}

The IDC (in this case the DGHEI machine), grabs periodically or by request, the lecturers data from each IDP/campus. The use of the campus server as an IDP is strongly possible because most public/private university has their own web server/IP Public. 


\section{IMPLEMENTATION AND EXPERIMENT RESULT}

To prove the concept, we list the required applications. All of them are web applications in order to take advantage of their multiplatform intrinsic characteristic.

Because, it is needed a web server which provides the RESTful web service in order to use the REST protocol as an approach of providing data. This web application is developed with flask framework. With this framework, web application has been developed for simulating purposes.

\section{A. Lecturer Profile Creation as PDP.}

We simulate the require document which contents are simply personal information in our Lecturer Based Supportive Tool (LBST) [6]. The LBST, enables lecturers to create/update not only profiles, but also authoring learning materials in offline conditions or no need Internet connections. The simulation of the input of personal information into our LBST is shown in Fig. 5.

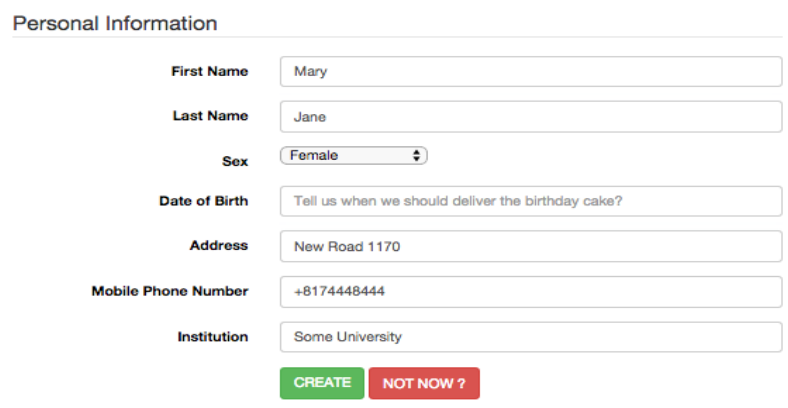

Fig. 5. Lecturer Profile's Data Entry.

\section{B. Uploading a Lecturer profile on IDP}

The next step to be done by the lecturer after authoring their public profile, is to upload it on IDP (Fig. 4 points B). For enable uploading data from PDP to IDP, a lecturer's laptop should establish a connection to the IDP web server. For this, the lecturer can upload the data by using LAN infrastructure or internet as long as IDP is accessible. The only lecturer's concern is to configure the IDP address. The configuration of our developed web application is shown in Fig. 6.

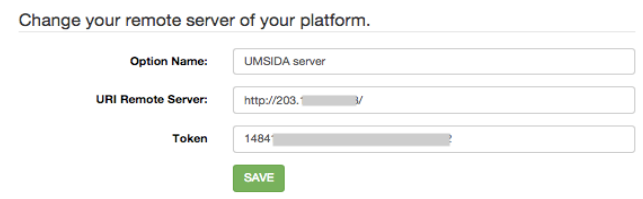

Fig. 6. Setting in PDP application.

\section{Grabbing Lecturer Profile Data.}

After connection is established and lecturer uploads their profiles, IDP provides the uploaded data automatically to IDC. IDC could grab the data accessing IDP web services. For example, in a URL: "http: //203.xxx.xxx.xx/people/". The IDP responses as shown in Fig. 7.

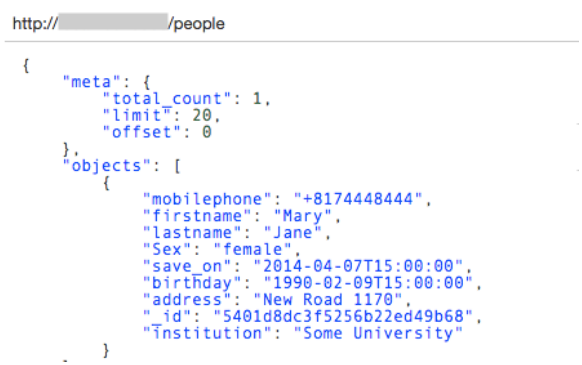

Fig. 7. Response from IDP. 
To use this response, we developed a third application that acts as IDC. With simulating the data grabbing process from the above response using python module called "requests" and "json.load" to parse the data. This parsed data we called Profile Datasets. Then save the downloaded data on a spreadsheet. In this experiment, we use Google Spreadsheet. By using Gspread, a python API for Google spreadsheet, we successfully store the Profile Datasets in Google Spreadsheet. Shown in Figure 8.

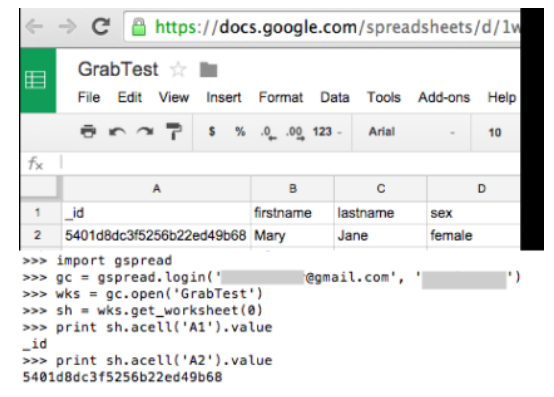

Fig. 8. Access Google Spreadsheet with python Gspread python module.

\section{CONCLUSION AND FUTURE WORK}

The present research proposes a method to collect lecturer's updated data and other administrative related academic information in a distributed. The benefits of using our proposed method could be, but not limited to: the DGHEI infrastructure will not achieve the "out of service" status, which allows the users to rely on the provided services without thinking in any disturbance in the uploading/retrieving processes since the new approach allows to distribute the load among the different campus servers. The simulations done so far, reinforces our research proposal in the way that there is no need to change drastically the installed infrastructure in academic institutions, but to only implement web services that could improve the general performance. We proved the high impact of the REST paradigm in order to solve a problem that is particular to the reality of Indonesian Higher Education Institutions.

As for our future work, we will emphasize the security in our uploading mechanisms. We will also will focus our efforts into the creation of a coordinated profile to be simulated. This coordination will be made with DGHEI in order to provide a much more reliable simulation.

\section{REFERENCES}

[1] L. O. Moreira, F. R. C. Sousa, and J. C. Machado, “A distributed concurrency control mechanism for XML data,” Journal of Computer and System Sciences, vol. 77, no. 6, pp. 1009-1022, Nov. 2011.

[2] C. Davis, "What if the Web Were Not RESTful?," in Proceedings of the Third International Workshop on RESTful Design, New York, NY, USA, 2012, pp. 3-10.

[3] Q. Z. Sheng, X. Qiao, A. V. Vasilakos, C. Szabo, S. Bourne, and X. Xu, "Web services composition: A decade’s overview,” Information Sciences, vol. 280, pp. 218-238, May. 2014.

[4] K. Gilly, C. Juiz, and R. Puigjaner, “An Up-to-date Survey in Web Load Balancing,” World Wide Web, vol. 14, no. 2, pp. $105-131$, Mar. 2011.

[5] Z. Guo, M. Su, Y. Xu, Z. Duan, L. Wang, S. Hui, and H. J. Chao, "Improving the performance of load balancing in software-defined networks through load variance-based synchronization," Computer Networks, vol. 68, pp. 95-109, Aug. 2014.

[6] I.A. Kautsar, S. Kubota, Y. Musashi, and K. Sugitani. “A Supportive Tool for Lecturers to Upload LMS Learning Contents Automatically.” 66th Joint Conference of Electrical, Electronics and Information Engineers in Kyushu. Kumamoto University, 2013. 